EESTI NSV TEADUSTE AKADEEMIA TOIMETISED. XVIII KOIDE

KEEMIA * GEOLOOGIA. 1969, NR. 3

ИЗВЕСТИЯ АҚАДЕМИИ НАУК ЭСТОНСКОН ССР. ТОМ ХVII

химия * ГЕология. 1969, № 3

\title{
Х. ПАЛЬМРЕ
}

\section{О МИКРОЭЛЕМЕНТАХ В ПИРИТОВЫХ И МАРКАЗИТОВЫХ КРИСТАЛЛАХ И КОНКРЕЦИЯХ ПАЛЕОЗОЙСКХ ОТЛОЖЕНИИ эстонии}

О составе микроэлементов в сульфидных минералах осадочных пород имеется мало спедений. Все известные материалы о распространении и концентрации микроэлементов в сульфидах железа изложены в работах К. Краускопфа (1955), Флейшера (Fleischer, 1955). Н. Страхова (1956), И. Гинзбурга (1957, 1960), Ярковского (Jarkovsky, 1964), Э. Дегенса (1967) и др. До настоящего времени имеется очень мало данных о распространении микроэлементов сульфидных минералов и конкреций в палеозойских отложениях Эстонской ССР. В связи с этим цель настоящей работы заключалась в том, чтобы лредставить некоторые данные о наличии и характере распространения элементов кобальта, никеля, мышьяка, свинца, цинка, меди, молибдена и марганца в пиритовых и марказитовых кристаллах и конкрециях, встречающихся в нижнекембрийских, ордовикских и силурийских отложениях Эстонии.

Образцы сульфидных минералов, кристаллы пирита и марказита, а также пиритовые и марказитовые конкреции отбирались по профилям обнажений с учетом их геологического положения и характера вмещающих пород. Помимо того, отдельные пробы были взяты из нескольких буровых скважин. В лаборатории собранный материал промывался разбавленной соляной кислотой для удаления посторонних примесей с поверхности кристаллов и конкреций. Пробы измельчались и из них под бинокулярным микроскопом отбирались для изучения мономинеральные фракции (более 1000 проб). Определение микроэлементов производилось в лаборатории спектрального анализа Института геологии АН ЭССР.

Для определения микроэлементов применялся кварцевый спектрограф ИСП-22. При сжигании проб использовался метод Э. Иоханнеса и Н. Миллера (1965). Применялись спектральные пластинки типа I, чувствительностью 1,4 по ГОСТу. Проявитель - стандартный. Время проявления 8 мин при температуре $+20^{\circ} \mathrm{C}$. Дешифровка спектрограмм производилась микрофотометром МФ-4.

Для определения элементов использовались следующие спектральные линии (в $\AA$ ): $\mathrm{Co}-3454 ; \mathrm{Ni}-3050 ; \mathrm{As}-2350 ; \mathrm{Pb}-2833 ; \mathrm{Zn}-3345 ; \mathrm{Cu}-3274 ; \mathrm{Mo}-3170$; $\mathrm{Mn}-2803$.

Спектральные анализы выполнены в основном химиком-спектроскопистом X. Пальцером.

В пределах отдельных стратиграфических единиц выделены пиритово-марказитовые кристаллы и конкреции, для которых вычислены средние содержания микроэлементов, определенные как средние арифметические из общего числа анализов проб. При этом предполагалось, что исследуемые минералы не содержат данного элемента в том случае, если последний не обнаружен количественным спектральным анализом. 
Средние содержания элементов в кристаллах и конкрециях пирита и марказита, встречающихся в отложениях кембрия, ордовика и силура Эстонии, приведены в таблице и графически интерпретированы на рисунке.
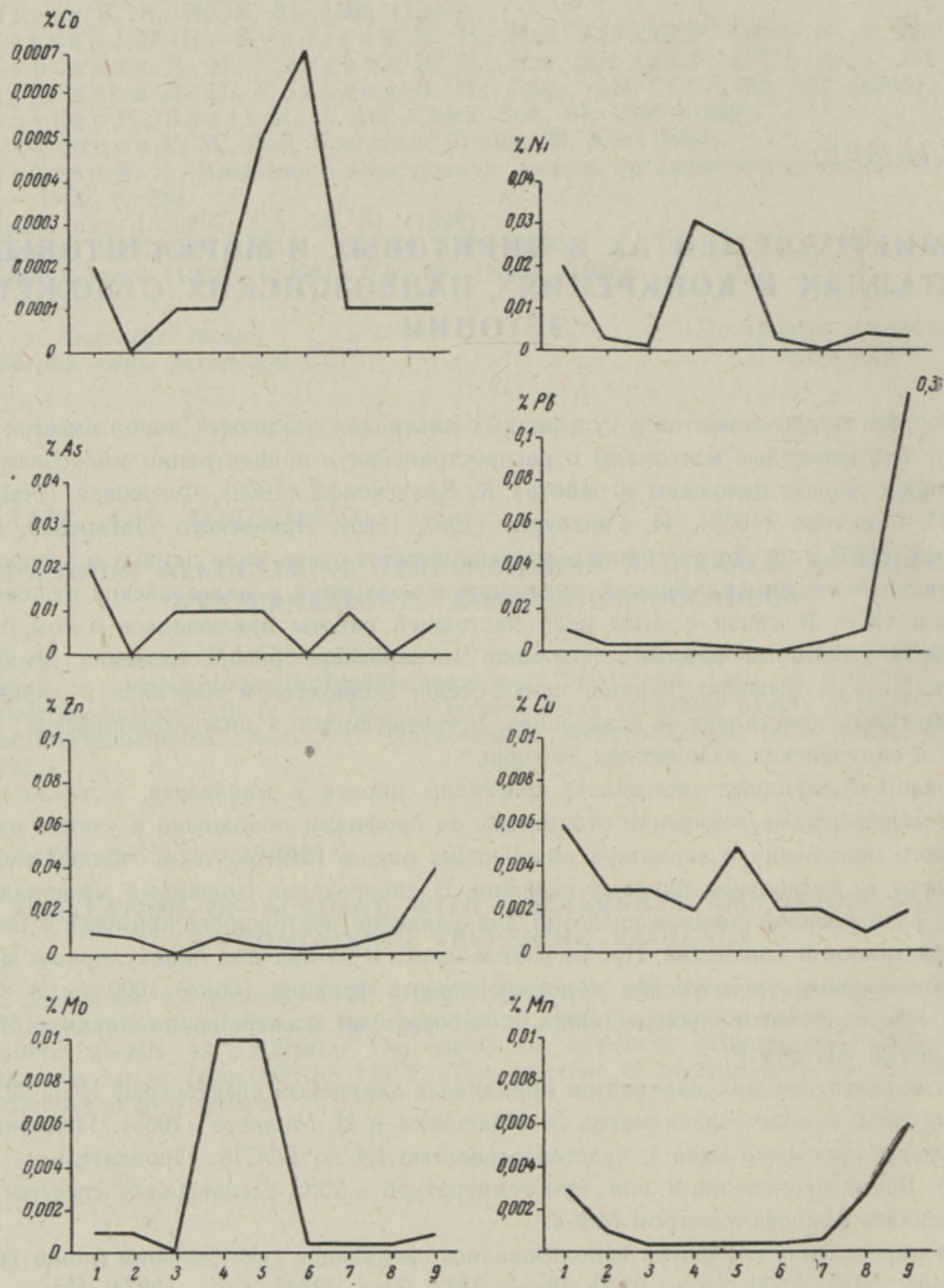

Среднее содержание микроэлеменгов в пиритовых и марказитовых кристаллах и конкрециях в осадочных породах.

1 - глины; 2 - кварцевые песчаникн; 3 - пиритовый слой; 4 - диктионемовый сланец; 5 - глауконитовая глина; 6 - мергелистые известняки; 7 известняки; 8 - доломиты; 9 - трещиноватые доломнты и известняки.

Упомянутые сульфидные образования сформировались в нижнекембрийских глинах и песчаниках, ордовикских и силурийских известняках, мергелистых известняках, мергелях и доломитах во время преобразования осадка в процессе диагенеза. 
Среднее содержание $\mathrm{Co}, \mathrm{Ni}, \mathrm{As}, \mathrm{Pb}, \mathrm{Zn}, \mathrm{Cu}, \mathrm{Mo}, \mathrm{Mn}$ в конкрециях и кристаллах пирита и марказита, \%

Геологический возраст, Характер горизонт, свита
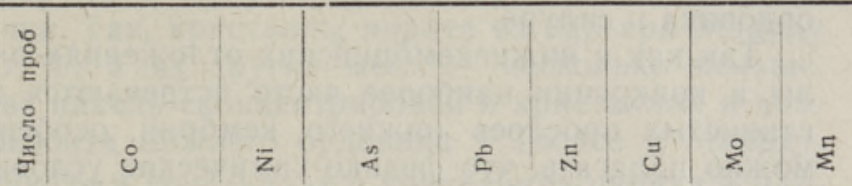

H. кембрнй, пнрнтаская свита, глины

Мийдурашна

Какумяэ

Савиранна

H. кембрий, тискреская

свита, песчаннкн

Тюрнсалу

Раннамын̈за

Лээтсе

Ижора (Ленннгр. обл.)

н. ордовик, пакерорт-

ский горизонт, пнрито-

вый слой

Скважина Тоолсе
Н. ордовик, тюрнсалу

H. ордовнк, тюрнсалу-
ская пачка, днктионе

мовын̆ сланец

Маарду, карьер

Маарду, карьер 2

Сака, штольня

Тюрисалу, обнажение

н. ордовик, лээтсеский

горизонт, глинистый

глауконитовый песча-

ник

Tоолсе, скважина

Maарду, карьер *

Сp. ордовик, ухакускнй горизонт, известняки

Вяо. каменоломня

Иыхвиский горизонт,

мергелистые известняки
Алувере, каменоломня

Алувере, каменоломня
В. ордовик, набаласки ̆

горизонт, известняки

Паупа, каменоломня

н. ордовик, кундаский горизонт, трещинова-

тые доломитизирован -

ные нзвестняки

Кунда-Ару, карьер*

С. ордовик, кукрузескин̆

горнзонт, трещиноватые доломитнзированные

известняки

Шахта Ni $_{8}$

Сиргала, карьер

Оандуский горнзонт

Падизе, карьер

н. силур, адаверескић̆ горизонт, трещннова тые доломиты

Навести I, обнажение

Навести IV, обнажение

Саастна, обнажение, мергелистые известняки

Яаннский горизонт

Лихула, скважнна

Муху, обнажение

B. силур, каармаскнй горизонт, доломиты Мустъяла, карьер Сельгузе, карьер

Каугатумаский горизонт

Oxecaаpe. скважина (гл. 55.05 м)

Oxесааре, скважина (гл. 228,3 $\boldsymbol{M}$ )

Oxесааре. скважина (гл. 221,94 $\mu$ )

Oxесааре, скважина (гл. 221,95 $\mu$ )

$\begin{array}{cc}\text { Конкрецин } & 69 \\ \text {,. } & 66 \\ \text { ". } & 20\end{array}$

Крнсталлы 4

".

Конкрецин $12 \quad 0,0001$

$0,001 \quad 0,01$

0,005

$\begin{array}{lllll}0,00183 & 0,0194 & 0,0072 & 0,001\end{array}$

$\begin{array}{lllll}0,0174 & 0,0231 & 0,0055 & 0,001\end{array}$

$\begin{array}{lllll}0,0165 & 0,017 & 0,008 & 0,001\end{array}$

0,001

$\begin{array}{lll}0,00021 & 0,0036 & 0,0287\end{array}$

Не обнар. $0,0135 \quad 0,0262$

Hе обнар. 0,008

", $, \quad 0,002$

$\begin{array}{ll}0,0002 & 0,0025 \\ 0,004\end{array}$

Не обнар.

$\begin{array}{llllll}. . & \text {. } & 0,004 & 0,010 & 0,0016 & 0,001 \\ . & 0,0026 & 0,010 & 0,0020 & 0,001\end{array}$

$0,014 \quad " \quad 0,0021 \quad 0,013 \quad 0,0087 \quad 0,001$

0,0011

0,0008

0,0016

0,00165

$-\quad 0,008 \quad 0.005$

0,0003

$\begin{array}{lll}. & 10 & 0,000 \\ , & 10 & 0,000 \\ , " & 15 & 0,000 \\ , & 12 & 0,000\end{array}$

$0,049 \quad 0,01$

$0,039 \quad 0,01$

$\begin{array}{llllllll}0,0001 & 0,037 & 0,01 & 0,007 & 0,012 & 0,003 & 0,001 & 0,0005 \\ 0,0001 & 0,004 & 0,01 & 0,005 & 0,006 & 0,002 & 0,042 & 0,0005\end{array}$

$\begin{array}{llllllll}0,0001 & 0,037 & 0,01 & 0,007 & 0,012 & 0,003 & 0,001 & 0,0005 \\ 0,0001 & 0,004 & 0,01 & 0,005 & 0,006 & 0,002 & 0,042 & 0,0005\end{array}$

0,005

0,0057

$\begin{array}{llllllll}0,0001 & 0,037 & 0,01 & 0,007 & 0,012 & 0,003 & 0,001 & 0,0005 \\ 0,0001 & 0,004 & 0,01 & 0,005 & 0,006 & 0,002 & 0,042 & 0,0005\end{array}$

$\begin{array}{llllllll}0,0001 & 0,037 & 0,01 & 0,007 & 0,012 & 0,003 & 0,001 & 0,0005 \\ 0,0001 & 0,004 & 0,01 & 0,005 & 0,006 & 0,002 & 0,042 & 0,0005\end{array}$

$\begin{array}{lll}0,027 & 0,005 & 0,017\end{array}$

$\begin{array}{llll}0,029 & 0,0012 & 0,0031\end{array}$

$\begin{array}{llllllll}0,0001 & 0,037 & 0,01 & 0,007 & 0,012 & 0,003 & 0,001 & 0,0005 \\ 0,0001 & 0,004 & 0,01 & 0,005 & 0,006 & 0,002 & 0,042 & 0,0005\end{array}$

$\begin{array}{llllllll}0,0001 & 0,037 & 0,01 & 0,007 & 0,012 & 0,003 & 0,001 & 0,0005 \\ 0,0001 & 0,004 & 0,01 & 0,005 & 0,006 & 0,002 & 0,042 & 0,0005\end{array}$

0,0005

0,0005

$\begin{array}{llllllll}0,0001 & 0,037 & 0,01 & 0.007 & 0,012 & 0,003 & 0,001 & 0,0005 \\ 0,0001 & 0,004 & 0,01 & 0,005 & 0,006 & 0,002 & 0,042 & 0,0005\end{array}$

Крнсталлы 30,0004

0,01

0,002

$0,002 \quad 0,11 \quad 0,01$

$\begin{array}{llll}0,001 & 0,003 & 0,0015 & 0,01\end{array}$

0,0005

0,0005

Конкрецин

Крнсталлы

Не обнар.

Следы

He $0,0018 \quad 0,0012 \mathrm{He}$

0,001

обнар. onp.

$\begin{array}{llll}0,001 & 0,002 & 0,003 & 0,001\end{array}$

0,005

$\begin{array}{llll}0,005 & 0,008 & 0,002 & 0,0005\end{array}$

0,0007

$0,0006 \quad 0,01$

0,018

$\begin{array}{lll}0,0625 & 0,0024 & 0,001\end{array}$

0,0036

$13 \quad 0,0005$

$0,0013 \quad 0,01$

0,283

0,556

$\begin{array}{lll}0,0779 & 0,0043 & 0,001\end{array}$

$\begin{array}{lll}0,016 & 0,0003 & 0,103\end{array}$

0,0145

$\begin{array}{rr}122 & 0,0005 \\ 3 & 0,0001\end{array}$

$0,001 \quad 0,01$

0,105

$\begin{array}{lll}0,0065 & 0,0016 & 0,0014\end{array}$

0,0198

".
".
$"$,
$"$,

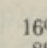

$\begin{array}{rr}169 & 0,0001 \\ 88 & 0,0001\end{array}$

$0,0064 \quad 0,0046$

$0,0013 \quad 0,0056$

0,113

0,642

$\begin{array}{llll}0,148 & 0,0026 & 0,0004 & 0,0004\end{array}$

$235 \quad 0,0007 \quad 0,0013 \quad 0,0003$

$\begin{array}{llllll}0,0005 & 0,0027 & 0,0021 & 0,0001 & 0,0056\end{array}$

20 Не обнар. $0,03220,008$

$\begin{array}{lllll}0,0079 & 0,0023 & 0,0077 & 0,0001 & 0,0018\end{array}$ $0,0001 \quad 0,0014$

He $\begin{array}{lllllllll} & 0,0001 & 0,0024\end{array}$

\begin{tabular}{|c|c|c|c|c|c|c|c|c|c|}
\hline рнсталлы & 1 & 0,0005 & 0,001 & , & $\begin{array}{l}\text { He } \\
\text { обнар. }\end{array}$ & 0,0017 & 0,0053 & & onp 0,001 \\
\hline Сонкреции & 1 & 0,0005 & 0,0006 & Следы & 0,008 & 0,0022 & 0,0012 & & , 0,001 \\
\hline нсталль & 1 & Не обнар. & 0,0005 & , & 0,002 & 0,0024 & 0,0012 & & 0,0 \\
\hline & 1 & ," & 0,0006 & " & 0,008 & 0,0020 & 0,0008 & & \\
\hline
\end{tabular}

- Во всех пробах содержнтся много кварца. 
В карбонатных породах кристаллы пирита и марказита встречаются в небольших количествах в основном на границах отдельных горизонтов ордовика к силура.

Так как в нижнекембрийских отложениях рассматриваемые кристаллы и конкреции наиболее часто встречаются в самых верхних частях глинистых прослоев нижнего кембрия, особенно в пиритаской свите, можно полагать, что физико-химические условия, кислотность и щелочность осадочной среды в конце нижнего кембрия часто менялись.

Қроме того, в Эстонии пиритовые и марказитовые агрегаты встречаются в тектонически трещиноватых зонах ордовика и силура, но, как показывают более ранние исследования автора (Пальмре, 1964, 1967), эти агрегаты образовались, по всей вероятности, в гипогенных рудоносных растворах.

Согласно данным И. Гинзбурга (1957), Э. Дегенса (1967) и других авторов, содержание микроэлементов в решетках минералов зависит от строения решеток, радиусов микроэлементов, способности их к изоморфному замещению. Оно различно для разных элементов и минералов и зависит, кроме того, от типа породы.

При сопоставлении содержания микроэлементов в пиритовых и марказитовых кристаллах и конкрециях, собранных нами из разных горизонтов кембрия, ордовика и силура Әстонии и из разной литологической среды, выявляются особенности концентрации микроэлементов в сульфидных образованиях железа (см. таблицу).

Кобальт. Наиболее часто этот элемент концентрируется в пиритовых и марказитовых конкрециях и кристаллах, образовавшихся среди глин, алевролитов и мергелистых известняков. В нижнекембрийских глинах и алевролитах он встречается только в конкрециях какумягиской пачки, где содержание его достигает $2 \cdot 10^{-4} \%$. В тискреской свите, у Тюрисалу, Раннамыйза и Лээтсе, где пиритовые кристаллы в конкреции включены в алевритовые прослойки кварцевого песчаника, кобальт отсутствует. В Ленинградской области, в обнажении у реки Ижора, в кристаллах пирита найдено $2 \cdot 10^{-4} \%$ кобальта.

Более постоянно его содержание в кристаллах и конкрециях пирита, встречающихся среди диктионемового сланца $\left(1 \cdot 10^{-1} \%\right)$.

В глауконитовых глинах лээтсеского горизонта пирит распространяется в виде небольших конкреций и кристаллов, содержащих кобальта до $5 \cdot 10^{-4} \%$.

В кристаллах и конкуренциях из известняков кобальта содержится до $1 \cdot 10^{-4} \%$, а из мергелистых известняков и мергелей адавереского горизонта у Саастна - $7 \cdot 10^{-4} \%$ и из мергелистых известняков яаниского горизонта - только $1 \cdot 10^{-4} \%$.

Кобальт в пиритовых конкрециях из Мустъяла не обнаружен, а в конкрециях из карьера Сельгузе его содержится $1 \cdot 10^{-4} \%$. Довольно низкое $\left(1 \cdot 10^{-4} \%\right)$ содержание кобальта характерно для пиритовых и марказитовых кристаллов, встречающихся в трещинах и кавернах в районах полиметаллического рудопроявления Северо-Восточной и Центральной Эстонии.

Никель. По сравнению с кобальтом никель распространяется в пиритовых и марказитовых образованиях более равномерно. В пиритовых конкрециях пиритаской свиты нижнего кембрия у Мийдуранна содержание никеля достигает $2,21 \cdot 10^{-2}$, а у Какумяэ, где конкреция пирита распространяется среди алевритов, - только $3,6 \cdot 10^{-3}$.

Қристаллы пирита из кварцевого песчаника нижнего кембрия у Тюрисалу содержат никеля $8 \cdot 10^{-3} \%$, у Раннамыйза, Лээтсе и у реки Ижо- 
ра - значительно меньше. Сравнительно много никеля имеется в пиритовых кристаллах и конкрециях, сформировавшихся в диктионемовом сланце тюрисалуской пачки. Так, кристаллы пирита из карьера Маарду содержат никеля $4,9 \cdot 10^{-2} \%$, а из других мест - несколько меньше. В повышенном количестве никель сконцентрирован в кристаллах и конкрециях лээтсеского горизонта нижнего ордовика у Тоолсе и Маарду.

Сравнительно мало никеля в кристаллах и конкрециях пирита и марказита, образовавшихся в карбонатной среде, в известняках, мергелистых известняках и доломитах. В тектонических трещиноватых известняках и доломитах пиритовые кристаллы также содержат сравнительно мало никеля $\left(1 \cdot 10^{-3} \%\right)$.

Мышьяк. В пиритовых и марказитовых конкрециях из нижнекембрийских глин содержание мышьяка - выше кларковой концентрации, а в кристаллах и конкрециях из нижнекембрийских кварцевых песчаников он ведет себя, как кобальт. Согласно данных Э. Дегенса (1967), можно полагать, что мышьяк в глинах, по-видимому, первоначально накапливается в гидроокислах железа, которые в глинах встречаются чаще, чем в кварцевых песчаниках. В конкрециях и кристаллах диктионемового сланца, пиритового слоя, глауконитового песчаника (глинистого) и известняков мышьяк накапливается в сульфидах железа в количествах выше кларковой концентрации.

В пределах кларковой концентрации мышьяк встречается только в кристаллах пирита и мергелистых известняках и мергелях у Саастна, а в доломитах он отсутствует или там имеются только его следы. В пиритовых кристаллах из трещиноватых карбонатных пород содержание мышьяка колеблется в широких пределах.

Свинец. Распространение свинца в пиритовых и марказитовых кристаллах и конкрециях довольно низкое и удерживается на уровне кларка. Пиритовые конкреции нижнекембрийских глин содержат свинца до $1,8 \cdot 10^{-2} \%$, а в кристаллах и конкрециях, образовавшихся среди нижнекембрийских песчаников, диктионемового сланца, известняков и мергелей, его иногда бывает меньше. Пиритовые конкреции из верхнесилурийских доломитов у Мустьяла и Сельгузе содержат свинца до $1 \cdot 10^{-2} \%$. Относительно высокое содержание свинца в пиритовых кристаллах обнаружено в трещинах и кавернах тектонических трещиноватых доломитизированных известняков и доломитов ордовика и силура.

На основе приведенных данных анализов можно отметить, что пирит из тектонически трещиноватых доломитов явно отличается от пирита, возникшего среди палеозойских осадочных отложений в процессе диагенеза. Пирит и марказит, встречающиеся в трещиноватых зонах, на стенках каверн и в прожилках, по всей вероятности, образовались из гипогенных рудоносных растворов, и свинец в них содержится в виде изоморфных примесей в кристаллических решетках. Пока еще не ясно, какая часть валового содержания свинца входит в решетку минерала и какая образует с ним изоморфную смесь.

Цинк. В пиритовых и марказитовых кристаллах и конкрециях цинк концентрируется аналогично свинцу. Его содержание в конкрециях пирита из нижнекембрийских глин доходит до $2,3 \cdot 10^{-2} \%$, а в нижнекембрийских кварцевых песчаниках составляет $1,8 \cdot 10^{-2} \%$. Пиритовые кристаллы и конкреции, развитые среди диктионемовых сланцев, содержат цинка максимально $2,9 \cdot 10^{-2} \%$, а образовавшиеся среди глинистых глауконитовых песков, известняков и мергелистых известняков - несколько меньше. 
Пиритовые конкреции из верхнесилурийских доломитов содержат цинка $1,5 \cdot 10^{-2} \%$.

Относительно высоко содержание цинка в пиритовых кристаллах, возникших в трещинах и кавернах трещиноватых доломитов ордовика и силура.

Результаты анализа пиритовых кристаллов из трещиноватых зон (см. таблицу) показывают, что по содержанию цинка они резко отличаются от кристаллов, образовавшихся среди палеозойских осадочных пород в процессе диагенеза.

Медь распространяется в кристаллах и конкрециях пирита и марказита в пределах кларковой концентрации. Несколько повышенное содержание меди отмечается в сульфидных образованиях среди нижнекембрийских глин и алевролитов $\left(8 \cdot 10^{-3} \%\right)$.

Молибден, Содержание молибдена в кристаллах и конкрециях сульфидов железа - низкое и иногда удерживается на уровне кларковых концентраций. В конкрециях и кристаллах из нижнекембрийских глин и песчаников количество его доходит до $1 \cdot 10^{-3} \%$, а в известняках, доломитах и мергелях его меньше - $1 \cdot 10^{-4} \%$. Немного больше молибдена обнаружено в пиритовых конкрециях, образовавшихся среди диктионемовых сланцев и глауконитовых глинистых песчаников. Особенно высокое содержание молибдена в пиритах диктионемового сланца можно связать с органическим веществом сланца.

Марганец распределяется в сульфидных конкрециях и кристаллах сравнительно равномерно. В конкрециях из нижнекембрийских глин его содержится до $6,3 \cdot 10^{-3} \%$, а в кварцевых песчаниках нижнего кембрия несколько меньше.

В мергелистых известняках и мергелях марганца содержится в конкрециях $5,6 \cdot 10^{-3} \%$, а в диктионемовом сланце и глауконитовых песчаниках - только $5 \cdot 10^{-4} \%$. Марганец, как и другие элементы, больше концентрируется в глинах, чем в песчаниках. В общем концентрация марганца в сульфидах железа ниже кларковой. В тектонически трещиноватых зонах, в кристаллах, образовавшихся из гипогенных растворов, концентрация марганца колеблется и иногда доходит до $1,9 \cdot 10^{-2} \%$. Такое колебание, по всей вероятности, показывает, что эти растворы не всегда содержали одинаковое количество марганца.

Из приведенных данных анализов выясняется, что концентрация указанных элементов в осадочных сульфидах железа в общем подчиняется законам осадкообразования. Согласно Н. Страхову (1956), Э. Дегенсу (1967) и другим авторам, увеличение содержания элементов в осадочных породах возрастает от песков к известнякам, мергелям и глннам.

Наши исследования показывают, что концентрация всех изученных элементов увеличивается по-разному, в зависимости от характера породы (см. рисунок). Выяснилось также, что пиритовые кристаллы и конкреции, образовавшиеся среди песчаников, содержат мало Co, $\mathrm{Ni}$, As, $\mathrm{Pb}, \mathrm{Zn}, \mathrm{Cu}$ и Mn. Содержание этих элементов выше в конкрециях, сформировавшихся в глинах.

Несколько иначе ведет себя молибден, который встречается больше в кристаллах пирита, образовавшихся в осадке с большим содержанием органики.

Исключение составляют $\mathrm{Pb}, \mathrm{Zn}, \mathrm{Mn}$, которые в бо́льших количествах встречаются в пиритовых и марказитовых кристаллах, возникших в трещинах и кавернах доломитов и доломитизированных известняков. Такое обогащение кристаллов пирита элементами $\mathrm{Pb}, \mathrm{Zn}$ й $\mathrm{Mn}$ можно объяснить накоплением их из гидротермальных растворов, проникавших в трещиноватые осадочные породы. 
На основании результатов изучения микроэлементов в пиритовых и марказитовых кристаллах и конкрециях палеозойских отложений Эстонии можно сделать следующие выводы:

1. Микроэлементы в пиритовых и марказитовых кристаллах и конкрециях находятся в пределах кларковой концентрации элементов в осадочных породах.

2. Пиритовые и марказитовые кристаллы и конкреции в глинах и аргиллитах всегда содержат больше микроэлементов, чем кристаллы и конкреции, образовавшиеся среди известняков и кварцевых песчаников.

3. Значительная концентрация свинца, цинка и марганца в кристаллах пирита и марказита установлена в тектонически трещиноватых зонах карбонатных пород ордовика и силура, особенно в местах распространения свинцово-цинковых рудопроявлений.

4. Свинец, цинк и марганец в пиритовых кристаллах из трещиноватых карбонатных пород являются элементами-индикаторами, которые могут служить надежными признаками при понсках полиметаллических оруденений.

\section{ЛИТЕРАТ У РА}

Ги н з бург И. И. 1957. Опыт разработки теоретических основ геохимических методов ноисков. М., Госгеолтехиздат.

Г и н з б у рг И. И. 1960. Геохимические поиски слепых рудных тел. Доклады советских геологов XXI сессии Междунар. геол. конгресса. Проблема 2. Геологические результаты прикладной геохимии и геофизики. М., Госгеолтехиздат.

Д еген с Э. Т. 1967. Геохимия осадочных образсваний. М., «Мир».

К р а уско п ф К. 1955. Осадочные месторождения редких металлов. Проблемы рудных месторождений. Изд-во иностр. лит.

И оханнес Э., Миллер А. 1965. Групповое концентрирование микроэлементов смесью сульфида и карбоната кадмия при химико-спектральном анализе кукерсита. Изв. АН ЭССР, Сер. физ.-матем. и техн, наук, 14, № 2.

Пі альм ре Х., Иоханнес Э. 1964. О некоторых микроэлементах в сульфидных минералах Эстонии. В сб.: Литология палеозойских отложеннй Эстонии.

ГІ альм р е X. 1967. Текстурные особенности руд свинцово-цинкового рудопроявления в Эстонской ССР. Изв. АН ЭССР, Сер. Хим. Геол., 16, № 3.

С тр́ а хов Н. М. 1956. К познанию диагенеза. Вопросы минералогии осадочных образований, кн. 3 и 4 . Изд. Львов, ун-та.

Fleischer M., 1955. Minor elements in some sulphide minerals. Econ. Geol,, 50, II. Jarkovsky Jan, 1964. Die Verteilung der Spurenelemente in den Pyriten und ihre geochemische Bedeutung beim Studium der Bildungsweise der Lagerstätten der Westkarpaten, Geol. Sborník, 15, 1. Bratislava.
Институт химии
Академии наук Эстонской ССР
Поступила в редакцию 17/IV 1968

\section{H. PALMRE}

\section{MIKROELEMENTIDEST PORIIDI JA MARKASIIDI KRISTALLIDES JA KONKRETSIOONIDES EESTI PALEOZOIKUMI SETETES}

Esitatakse mōningad andmed koobalti, nikli, arseeni, plii, tsingi, vase, molübdeeni ja mangaani esinemisest mikroelementidena Eestis püriidi ja markasiidi kristallides ja konkretsioonides. Nende elementide kogus püriidis ja markasiidis vastab enamasti elementide klargilisele sisaldusele settekivimites. Mikroelementide koondumine püriidi ja markasiidi kristallidesse ja konkretsioonidesse on tōenäoliselt toimunud adsorptsiooni teel ning allub üldistele sedimentatsiooni ja kivimi kujunemise seaduspärasustele.

Selgus, et püriidi ja markasiidi kristallid ja konkretsioonid, mis on kujunenud savises keskkonnas, sisaldavad alati rohkem mikroelemente kui need, mis on tekkinud liiva ja lubjakivides. 
Peale tavalise püriidi, mis esineb lubjakivides ja dolomiitides diskontinuiteedi pindadel ja kavernides, leidub Eestis püriiti ja markasiiti ka väikeste maagisoontena.

Spektraalanalüüs näitas, et Kesk- ja Kirde-Eesti maagisoontest saadud püriit sisaldab kōrgendatud kontsentratsioonis pliid, tsinki ja mangaani. Lähtudes eespool esitatust, vōiks neid elemente pidada maagistunud piirkondade indikaatoriteks, mis vôivad osutada polümetallilisele maagiilmingule aluspõhjas.

\section{H. PALMRE}

\section{ON TRACE ELEMENTS IN PYRITE AND MARCASITE CRYSTALS AND CONCRETIONS IN PALEOZOIC SEDIMENTS OF THE ESTONIAN SSR}

The author presents some data on the occurrence, in the role of trace elements, of cobalt, nickel, arsen, lead, zinc, copper, molybdenum and manganese in the crystals and concretions of pyrite and marcasite in the Estonian SSR. The amount of those elements in pyrite and marcasite on the whole corresponds to the clarke values of elements in sedimental rocks. The concentration of trace elements in the crystals and concretions of pyrite and marcasite was probably effected in the way of adsorption according to general laws of sedimentation and formation of rocks.

It has been stated that the crystals and concretions of pyrite and marcasite formed in a clayey medium are always richer in trace elements than those formed in sandstones and limestones.

By the side of ordinary pyrite occurring in limestones and dolomites on discontinuity surfaces and in caverns, pyrite and marcasite occur in Estonia in small ore veins.

As revealed by spectral analysis, the pyrite obtained from small ore veins in Central and Northeast Estonia contains lead, zinc and manganese in heightened concentrations. Proceeding from the above, those elements might be considered to be indicator elements of mineralization areas, which might point to an occurrence of polymetallic ores in the bedrock. 